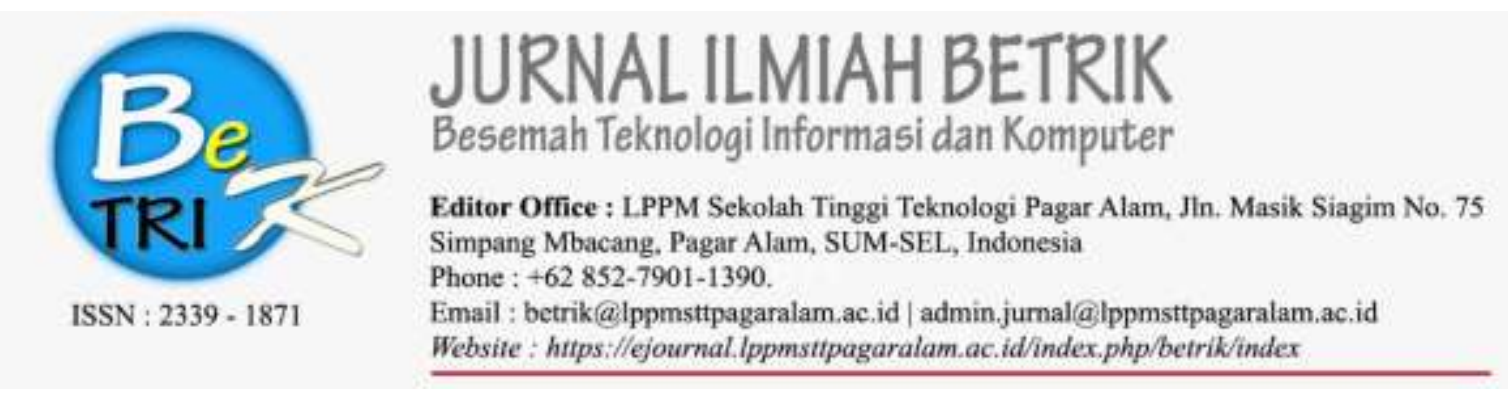

\title{
RANCANG BANGUN WEBSITE SEKOLAH DENGAN METODE USER CENTERED DESIGN (UCD) Yogi Isro' Mukti
}

Program Studi Teknik Informatika Sekolah Tinggi Teknologi Pagar Alam JalanMasik Siagim No.75 Simpang Mbacang Kec.Dempo Tengah Kota Pagar Alam

Sur-el : yogie.isro.mukti@sttpagaralam.ac.id

\begin{abstract}
Abstrak: Tujuan dari penelitian ini adalah merancang dan membangun website Sekolah pada SMP Negeri 1 Sekayu. Website merupakan sarana informasi bagi organisasi dalam meningkatkan layanan, sebagaimana SMP Negeri 1 Sekayu mengembangkan layanan online berbasis web guna meningkatkan kualitas organisasi sekolah. Suapaya bisa berjalan baik maka perlu metode yang menyelaraskan sesuai kebutuhan, salah satunya adalah dengan metode user centered design (UCD). Dan perancangan menggunakan metode Unified Modelling Language (UML), dalam pembangunan database menggunakan MySQL dan bahasa pemrograman menggunakan php. Penelitian ini menghasilkan website sekolah yang dinamis sesuai dengan metode yang dikembangkan.
\end{abstract}

Kunci Utama: Website,SMP Negeri 1 Sekyu, user centered design (UCD), UML.

\begin{abstract}
The purpose of this research is to design and build a School website at Sekayu 1 Middle School. The website is a means of information for organizations in improving services, as SMP Negeri 1 Sekayu develops web-based online services to improve the quality of school organizations. If it can work well, it needs to harmonize the method as needed, one of which is the user centered design (UCD) method. And the design uses the Unified Modeling Language (UML) method, in database development using MYSQL and the programming language using php. This research produces a dynamic school website according to the method developed.
\end{abstract}

Keywords : Website, SMP Negeri 1 Sekyu, usability, user centered design (UCD), UML.

\section{PENDAHULUAN}

Website merupakan salah satu media penyampaian informasi dan publikasi yang mudah diakses dari mana saja, kapan saja tanpa terbatas oleh wilayah geografis yang dapat dimanfaatkan oleh sekolah. Website adalah sebuah media presentasi online untuk sebuah perusahaan atau individu, website juga dapat digunakan sebagai media informasi secara online. (Komang Wiswakarma, 2009).

SMP Negeri 1 Sekayu merupakan Sekolah yang sudah memanfaatkan website sebagai sarana penunjang informasi bagi sekolah, yang menghubungkan antara guru, 
siswa dan sekolah dan masyaraka sebagai media edukasi. Manajemen sekolah sangat mengharapkan bahwa website ini dapat disajikan kepada siswa, guru dan masyarakat sebagai media interaktif. Untuk itu, sikap penerimaan terhadap website ini di kalangan internal sekolah, menjadi salah satu tolak ukur bagi manajemen sekolah.

Adapun batasan masalah antara lain, Penelitian ini membahas mengenai user centered design pada website SMP Negeri 1 Sekayu dan membandingkan nilai pengguna dari legalitas website SMP Negeri 1 Sekayu. Tujuan dari penelitian ini adalah Melakukan pengukuran user centered design (UCD) pada website SMP Negeri 1 Sekayu dan Mengusulkan rancangan model website SMP Negeri 1 Sekayu yang menitikberatkan pada hasil pengukuran user centered design (UCD).

\section{METODE PENELITIAN}

\subsection{Website}

World Wide Web atau WWW atau juga dikenal dengan web adalah salah satu layanan yang didapat oleh pemakai komputer yang terhubung ke internet. Website atau situs dapat diartikan sebagai kumpulan halaman-halaman yang digunakan untuk menampilkan informasi teks, gambar diam atau gerak, animasi, suara, dan atau gabungan dari semuanya itu baik yang bersifat statis maupun dinamis yang membentuk satu rangkaian bangunan yang saling terkait dimana masing-masing dihubungkan dengan jaringan-jaringan halaman (hyperlink)

\subsection{User Centred Design}

User Centred Design (UCD) adalah pendekatan desain, diadopsi oleh banyak industri untuk mengembangkan produk dan jasa yang akan memenuhi kebutuhan dan harapan para pengguna akhir. Namun, menerapkan pendekatan UCD tidak sepele, dan banyak industri masih tampak mengalami kesulitan dalam efektif menerapkan metode UCD dalam proses pembangunan mereka. Secara tradisional, fokus menerapkan UCD dalam industri telah pada pengembangan sistem yang akan digunakan dalam pengaturan bisnis dan pekerjaan bukannya pengembangan produk dan layanan yang ditujukan untuk digunakan oleh konsumen. Situasi ini tampaknya berubah bersama-sama dengan pengembangan produk dan layanan di manamana, dan oleh karena itu ada kebutuhan untuk memperjelas proses UCD dan membuat metode UCD lebih mudah diakses bagi perusahaan, terutama ketika merancang sistem dan produk untuk konsumen. (Heinila, Stromberg, Leikas and Ikonen : 2005)

\subsection{Konsep User Centred Design}

"In user user-centered design, the users are the center focus." Maksud dari pernyataan di atas adalah tujuan/sifat sifatsifat, konteks, penguna, sifat konteks dan lingkungan produk semua didasarkan dari pengalaman penguna Selanjutnya ditetapkan model pekerjaan pengguna yang akan didukung sistem sistem. Prinsip-prinsip dalam merancang user interface adalah sebagai berikut :

1. User familiarity / mudah dikenali : menggunakan istilah yang lazim 
digunakan dan dikenali oleh pengguna secara umum, misalnya: untuk sistem perkantoran gunakan istilah letters, documents, folders bukan directories, file, identifiers.

2. Consistency : Konsisten dalam operasi dan istilah yang digunakan di seluruh sistem sehingga tidak membingungkan.

3. Minimal surprise / Tidak membuat pengguna terkejut : Operasi yang terjadi dapat diprediksi oleh pengguna sesuai dengan perintah yang ada.

4. Recoverability/ pemulihan : Recoverability ada dua macam yaitu : confirmation of destructive action (konfirmasi terhadap aksi yang merusak) atau ketersediaan fasilitas pembatalan (undo).

5. User guidancel bantuan : Adanya cara penggunaan sistem sehingga pengguan lebih mudah dalam menjalankan sistem.

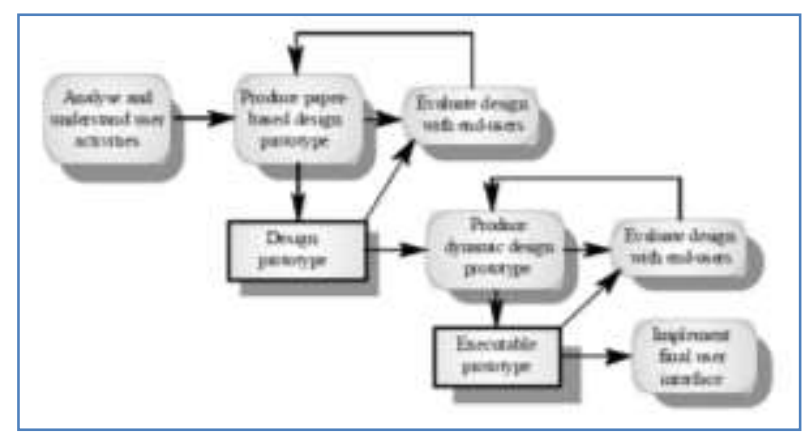

Gambar 1. Prinsip Perancangan UCD

\subsection{Metode Pengumpulan Data}

Dalam pengumpulan data untuk penelitian user centered design penggunaan website SMP Negeri 1 Sekayu, digunakan beberapa cara, yaitu:

1. Metode Observasi
Observasi dilakukan pada SMP Negeri 1 Sekayu dengan mengamati pengelolaan data-data yang dikelolah website SM Negeri 1 Sekayu.

2. Metode Wawancara

Dengan melakukan tanya jawab langsung dengan staf, guru dan siswa SMP Negeri 1 Sekayu

3. Metode Kuisioner

Pada metode ini kegiatan yang dilakukan adalah membuat beberapa pertanyaan untuk melakukan uji ketergunaan (usability) agar mengetahui tingkat penerapan layanan dan tingkat kemudahan penggunaan website SMP Negeri 1 Sekayu.

\subsection{Kerangka Berfikir Penelitian}

Agar rencana penelitian ini dapat dibuat dengan baik maka diperlukan suatu alur kerja yang dapat diimplementasikan dalam suatu organisasi. Kerangka kerja ini merupakan acuan yang akan di jadikan dalam menyusun analisa terhadap website SMP Negeri 1 Sekayu, yang berisi tahapan-tahapan : 


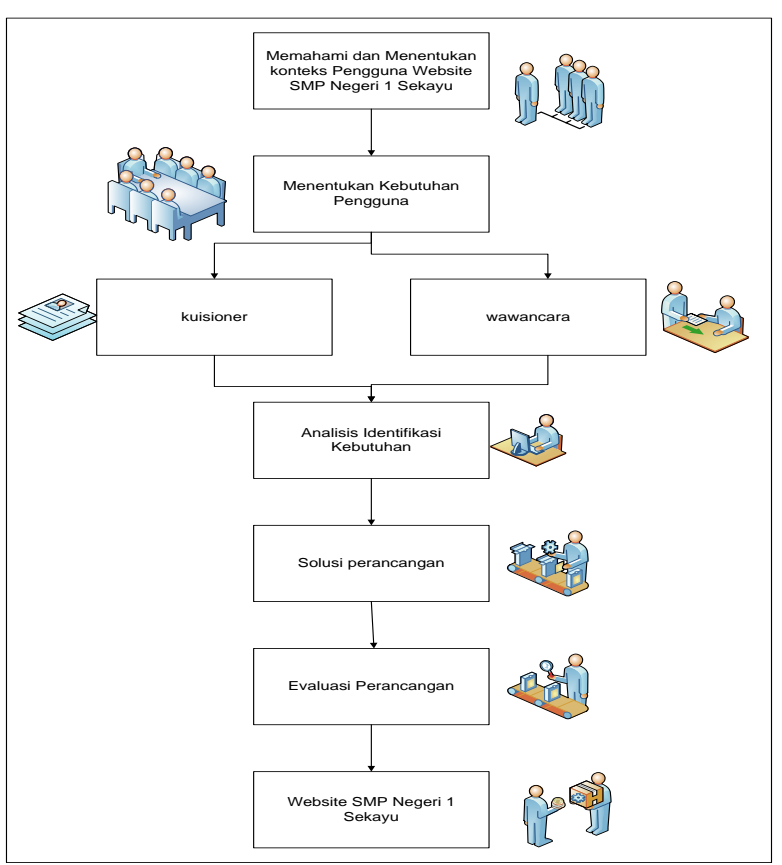

Gambar 2. Kerangka Pemikiran

1. Memahami dan Menentukan Konteks Pengguna

Pengguna pada aplikasi website SMP Negeri

1 Sekayu adalah bersifat umum dan hanya dapat digunakan oleh lingkungan SMP Negeri 1 Sekayu.

2. Menentukan Kebutuhan Pengguna

Pada umumnya website digunakan untuk berbagi informasi, namun saat ini website hanya menampilkan fitur yang memungkinkan pengguna berbagi informasi hanya dalam format teks saja. Di awal penelitian akan digunakan metode UCD untuk mengumpulkan data yang berkaitan dengan pengguna website.

3. Analisis Identifikasi Kebutuhan

Setelah menentukan kebutuhan pengguna, kemudian dianalisis yang menyesuaikan dengan kebutuhan, hal apa saja yang perlu dipersiapkan untuk menyelaraskan kebutuhan pengguna, agar memudahkan dalam proses perancangan.
4. Solusi Perancangan

Setelah dilakukan identifikasi, maka tahap selanjutnya adalah membuat perancangan aplikasi yang sesuai dengan hasil analisis sebelumnya, dengan membuat flowcart alur sistem yang akan di implementasikan.

5. Evaluasi Perancangan

Setelah dilakukan perancangan, tahap selanjutnya adalah melakukan evaluasi rancangan dari awal sampai akhir, apakah sudah sesuai dengan yang dibutuhkan

\section{HASILDAN PEMBAHSAN}

\subsection{Menentukan Konteks Pengguna}

Setelah di lakukan analisis, dalam menentukan konteks pengguna yang berhubungan langsung dengan pengguna sesungguhnya a, dalam hal ini adalah wawancara yang dapat ditarik kesimpulan bahwa saat ini SMP Negeri 1 Sekayu membutuhkan sebuah website yang bisa digunakan sebagai sarana penunjang kegiatan sekolah, yang menyesuaikan dengan kebutuhan pengguna dalam hal ini adalah para siswa dan guru. dan dari hasil kuesioner di dapatkan data sebagai berikut :

1. Para pengguna website tidak ada kesulitan dalam mengakses website SMP Negeri 1 Sekayu (80\%) menganggap mudah, (6\%) menganggap susah dan (2\%) tidak bisa.

2. Website SMP Negeri 1 Sekayu, cukup mudah untuk dimengerti karena $(>60 \%)$ pengguna hanya membutuhkan waktu kurang dari 7 hari untuk mengerti cara kerja SMP Negeri 1 Sekayu. 
3. Dilihat dari hasil kunjungan hampir semua pengguna mengakses Website SMP Negeri 1 Sekayu (50\%) menjawab tiap hari, (30\%) menjawab sekali dalam seminggu, (20\%) menjawab sekali dalam sebulan dan $(0 \%)$ menjawab tidak pernah mengunjungi.

4. Untuk hasil dari fungsi menu atas pengguna menjawab (50\%) sangat baik, (30\%) menjawab baik, (20\%) menjawab cukup baik dan (0\%) pengguna menjawab kurang baik.

5. Untuk hasil menu pencarian yang diletakan di atas pengguna menjawab $(80 \%)$ sangat baik, (14\%) menjawab baik, (6\%) menjawab cukup baik dan (0\%) menjawab kurang baik.

6. Untuk hasil tampilan slide swhow para pengguna menjawab (80\%) sangat baik, (8\%) menjawab baik, (6\%) menjawab cukup baik dan (6\%) menjawab kurang baik.

7. Untuk hasil tampilan sendiri (60\%) menjawab sangat pas, (28\%) menjawab pas, (6\%) menjawab kurang pas dan (6) menjawab tidak pas.

8. Untuk hasil fungsi login, (70\%) menjawab sangat baik, (20\%) menjawab cukup baik, (8\%) menjawab kuran, dan (2\%) menjawab tidak baik.

9. Untuk hasil desain tampilan, (70\%) menjawab sangat menarik, (20\%) menjawab cukup, (1\%) menjawab tidak menarik.

10. Untuk hasil tingkat kepusasan pengguna terhadap website SMP Negeri 1 Sekayu, (60\%) menjawab sangat pas, (28\%) menjawab pas, (6\%) menjawab kurang pas, dan (6\%) menjawab tidak pas.

\subsection{Analisis Identifikasi Kebutuhan}

Dari hasil wawancara terhadap Kepala SMP Negeri 1 Sekayu dan desain gambar terhadap website SMP Negeri 1 Sekayu yang dilakukan oleh siswa serta dilakukan kuesioner maka dapat dianalisis kebutuhan pengguna. Secara umum berikut hasil analisis kebutuhan pengguna website SMP Negeri 1 Sekayu.

1. Adanya sebuah permintaan dari para pengguna akan fasilitas chat, yang bisa digunakan untuk berkomunikasi ke sesama pengguna.

2. Adanya sebuah forum komunikasi, untuk tempat berdiskusi antar siswa dan guru serta para orang tua, sehingga tidak terikat oleh waktu.

3. Pengguna juga menyarankan agar terdapat fasilitas elearning.

\subsection{Solusi Perancangan}

\section{Task Modelling}

Pada aktivitas ini akan menggunakan task design, yang menggambarkan komunikasi antar fitur-fitur yang ditambahkan dengan website dan pengguna. Untuk task ini hanya akan menggambarkan fitur-fitur yang ditambahkan saja, berikut gambaran task design penambahan fitur pada website SMP Negeri 1 Sekayu yang akan ditambahkan

a. Fitur Chat 


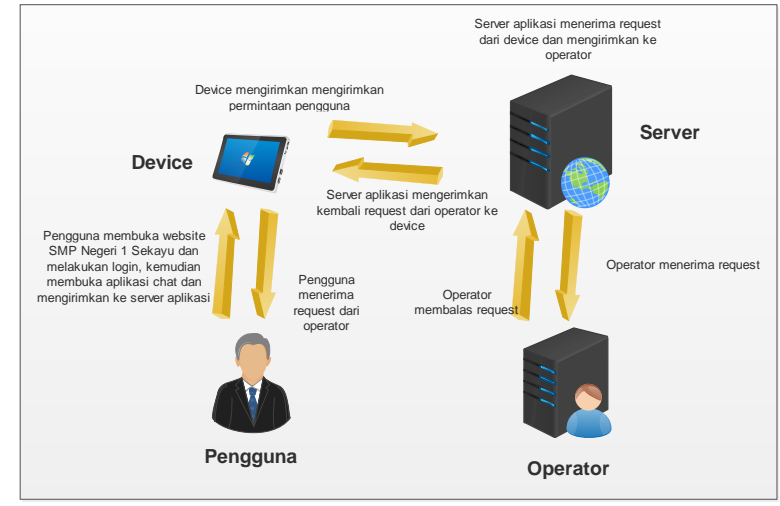

Gambar 3. Alur Fitur Chat

b. Fitur Forum

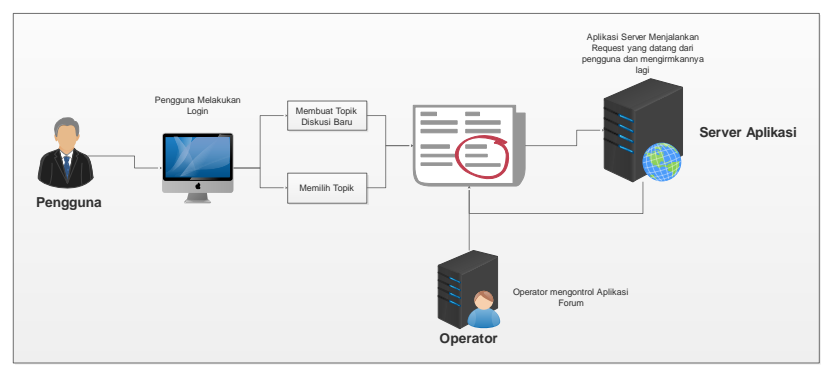

Gambar 4. Alur Fitur Forum

c. Fitur elearning

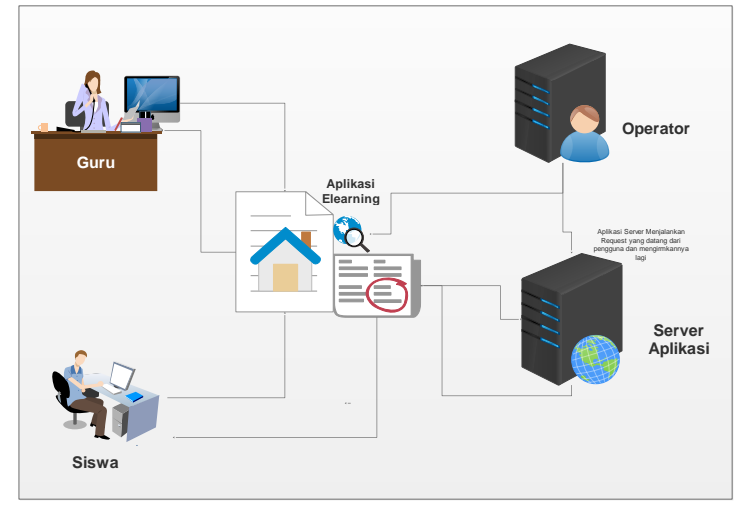

Gambar 5. Alur Fitur E-learning

Secara keseluruhan untuk penambahan model task design website SMP Negeri 1

Sekayu bisa dilihat pada gambar berikut :

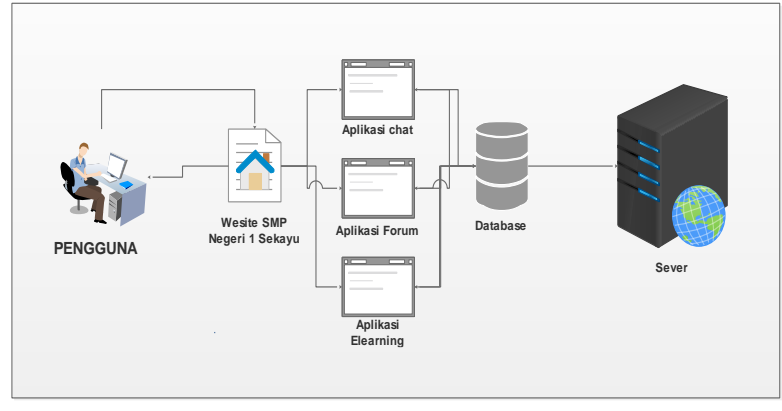

Gambar 6. Alur Fitur task design website SMP Negeri 1 Sekayu.

\subsection{Evaluasi Perancangan}

Berikut evaluasi kegunaan fitur yang dikembangkan pada aplikasi website SMP Negeri 1 Sekayu terhadap kebutuhan pengguna :

1. berdasarkan hasil kuesioner yang dilakukan, pengguna memberikan saran untuk komunikasi dengan pihak sekolah yang bisa dilakukan secara online maka perlu adanya penambahan fitur, yaitu menghadirkan fitur chat, diharapkan dengan adanya fitur ini komunikasi anatar pengguna website SMP Negeri 1 Sekayu bisa berjalan dengan baik, mengingat perkembangan teknologi komunikasi dan informasi yang semakin berkembang.

2. Untuk memberikan keleluasaan pengguna dalam berbagi informasi, aplikasi website SMP Negeri 1 Sekayu dilakukan penambahan fitur forum, fitur ini memungkinkan kepada sesama para pengguna website SMP Negeri 1 Sekayu bisa saling berdiskusi mengenai permasalahan terkait dengan kegiatan akademik di sekolah, dengan adanya fitur forum ini diharapkan komunikasi bisa 
berjalan dengan baik, karena sifatnya yang tidak formal orang tua siswa juga bisa melakukan diskusi kepada para tenaga pendidik yang ada di SMP Negeri 1 Sekayu, sehigga para orang tua juga berperan dalam melakukan pemantauan perkembangan akademik anaknya.

3. Agar proses belajar mengajar bisa berlangsung secara efektif, efesien agar prestasi akademik siswa bisa maksimal ini tentunya perlu waktu pengawasan yang tidak sedikit dan tidak bisa hanya dilakukan di sekolah saja, untuk itu maka perlu adanya sebuah sistem yang mampu mengontrol kegiatan siswa kapan saja dan dimana saja, oleh karena itu maka perlu adanya penambahan fitur elearning pada website SMP Negeri 1 Sekayu sebagai solusi. Diharapkan dengan adanya penambahan fitur ini dapat meningkatkan prestasi akademik siswa, karena proses belajar mengajar siswa bisa dimonitoring melalui aplikasi elearning.

\subsection{Rancangan Antar Muka}

Perancangan antar muka setelah dievaluasi dan pada website SMP Negeri 1 Sekayu, yang memiliki fungsi :

1. beranda untukk menampilkan halaman depan

2. profile, menampilkan profil SMP Negeri 1 Sekayu berupa sejarah sekolah dan visi misi serta struktur organisasi

3. berita, menampilkan berita yang berhubungan dengan SMP Negeri 1 Sekayu, atau dunia pendidikan sesuai dengan kategori berita
4. akademik, menampilkan jadwal, data siswa, guru dan proses akdemik di SMP Negeri 1 Sekayu

5. Forum, menampilkan form aplikasi forum sebagai sarana diskusi

6. Elearning, menampilkan form aplikasi elearning sebagai sarana pembelajaran

7. Download, menampilkan data file yang boleh di download.

8. UN, manmpilkan hasil evaluasi Ujian Nasional

9. PSB, menampilkan data Penerimaan Siswa Baru

10. Login, menampilkan form login

11. Form cari, menampilkan input pencarian

12. Foto kepala, menampilkan foto atau gambar Kepala Sekolah

13. Gambar Slide, menampilkan data gambar slide berita

14. Galeri foto, menampilkan foto atau gambar guru dan staf

15. Pengumuman, menampilkan data pengumuman

16. Content, menampilkan data content sesuai dengan link.

17. Jam, menampilkan aplikasi jam digital

18. Kalender, menampilkan daftar kalender aktif

19. Berita menampilkan data berita terpopuler dari sebelah kanan

20. chat, menampilkan data obrolan

21. video menampilkan data video

22. link, menampilkan data link ke halaman situs lain yang berhubungan dengan SMP Negeri 1 Sekayu

23. Kontak, menampilkan halaman kontak SMP Negeri 1 Sekayu 


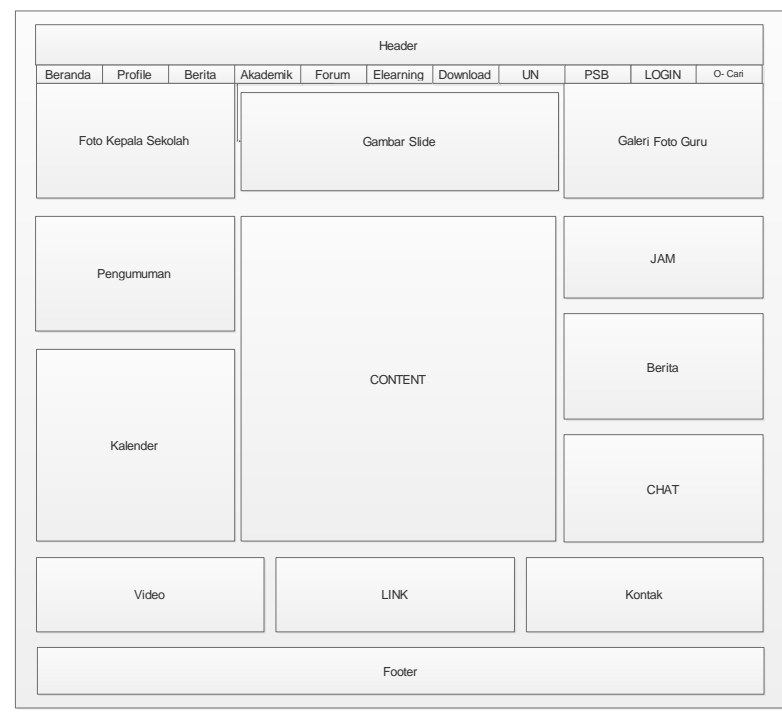

Gambar 7. Antar Muka Website SMP

Negeri 1 Sekayu

\subsection{Hasil Evaluasi Perancangan}

Perancangan adalah suatu proses yang bertujuan untuk menganalisis, menilai memperbaiki dan menyusun suatu sistem, baik sistem fisik maupun non fisik yang optimum untuk waktu yang akan datang dengan memanfaatkan informasi yang ada, adapun rancangan website SMP Negeri 1 yang ada meliputi bebarapa bagian, baik siswa mapun guru.

\section{A. Struktur Menu Front End}

Struktur menu ini merupakan struktur yang tampil ketika user mengakses website SMP Negeri 1 Sekayu, berikut urutan struktur menunya.

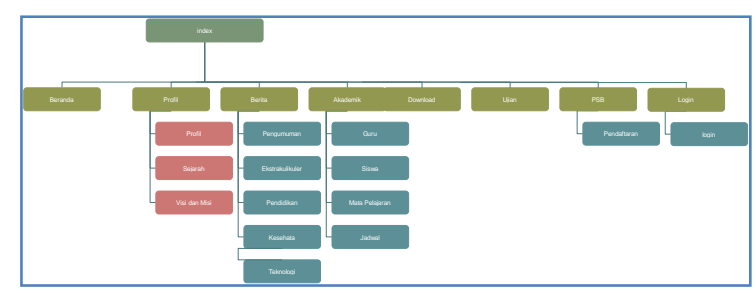

Gambar 8. Struktur File

Pada struktur file di atas terdapat file utama, menu utama dan sub menu utama, menu ini digunakan untuk memanggil fungsi yang ada di website SMP Negeri 1 Sekayu.

1. Index

Index merupakan file yang pertama kali akan dipanggil ketika program dijalankan, sehingga file data yang ada terhubung ke bagian index.

2. Beranda

Merupakan struktur menu yang digunakan untuk kembali ke halaman depan

3. Profil

Menu ini digunakan untuk memanggil identitas sekolah, memiliki sub menu digunakan untuk memanggil file, profil, sejarah dan visi misi

4. Berita

Menu ini digunakan untuk menampilkan berita, dan memiliki sub menu yang digunakan untuk memilih jenis berita

5. Akadmik

Menu ini digunakan untuk memanggil data akademik, dan memiliki sub menu guru, siswa, pelajaran dan jadwal

6. Download

Menu ini digunakan untuk mengunduh file yang ada di website SMPN 1 Sekayu

7. Ujian

Menu ini digunakan untuk memanggil data informasi ujian

8. PSB

Menu ini digunakan untuk membuka form pendaftaran bagi calon siswa baru

9. Login 
Menu ini digunakan untuk memanggil form login yang digunakan untuk masuk, baik kehalaman siswa maupun guru.

\subsection{Desain dan Tampilan}

Desain tampilan antar muka website SMP Negeri 1 Sekayu ini dibuat dengan menggunakan kerangka dasar desain framework Bootstrap dari twitter, yang dikombinasikan dengan library dari jQuery.

a. Tampilan Menu Utama

Berikut tampilan dari menu utama website SMP Negeri 1 Sekayu yang terdiri dari header, sidebar atas, sidebar kiri dan sidebar kanan, dan pada bagian tengah berisi konten serta footer di bagian bawah.

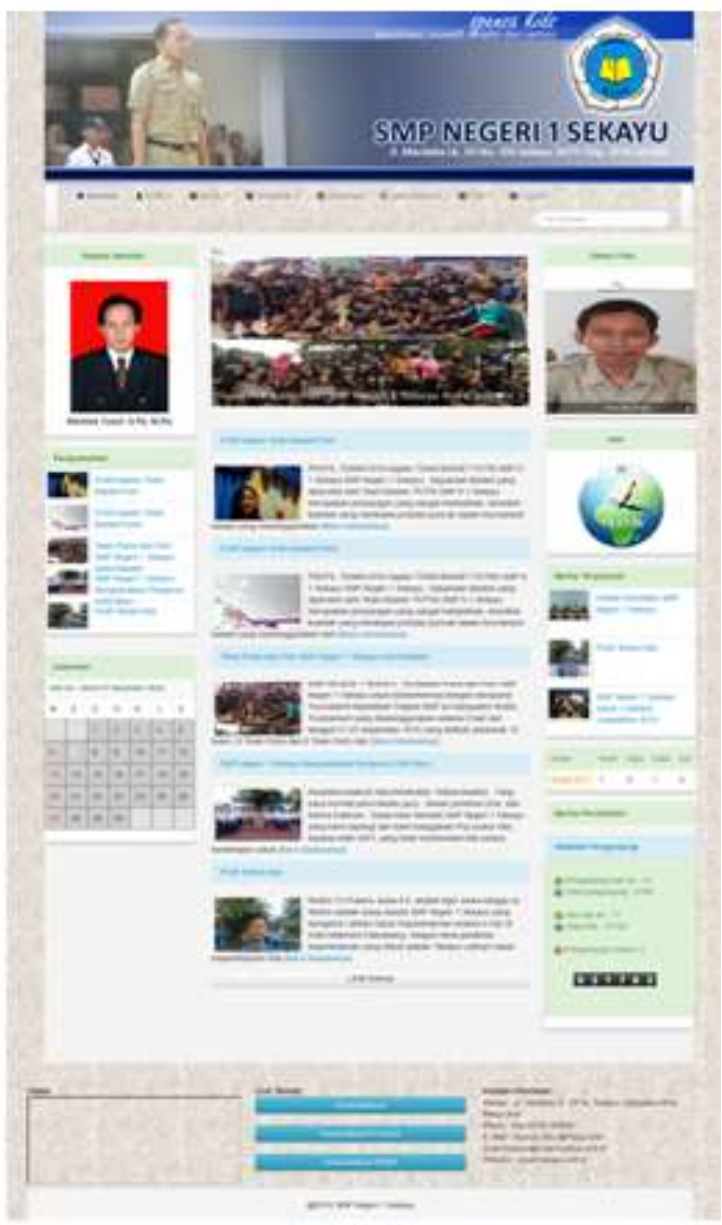

Gambar 9. Halaman muka b. Tampilan Sidebar Atas

Menu navbar ini digunakan untuk navigasi memnaggil menu yang ada, yang diletakan di atas konten di bawah header, hal ini dilakukan agar user mudah mengenali menu tersebut. Berikut tampilan navbar

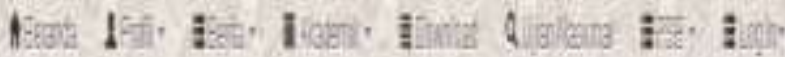

Gambar 10. Navbar menu atas

c. Tampilan Isi Konten

File kontent ini di letakan di bagian tengah, ketika sebuah perintah dari user memanggil file, maka konten yang berada di tengah akan aktif menampilkan request yang dilakukkan user. Berikut tampilan konten berita.

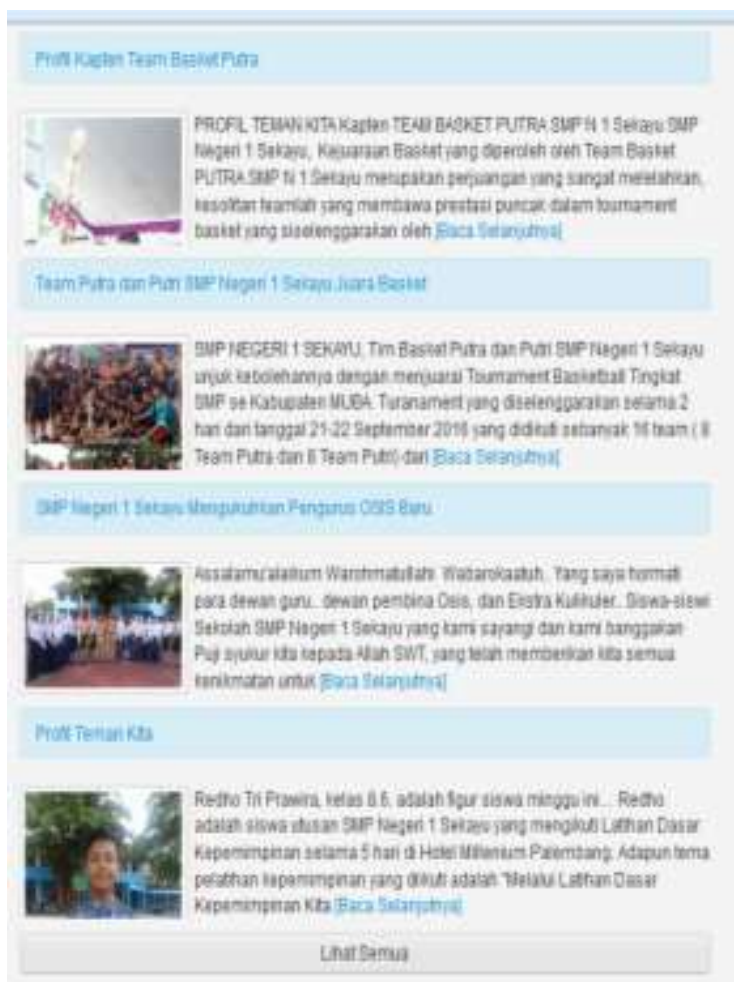

Gambar 11. Data Kontent tengah

d. Tampilan Sidebar Kiri

Pada sidebar sebelah kiri ini berisi foto Kepala Sekolah SMP Negeri 1 Sekayu, kemudian di bawah foto terdapat menu untuk 
menampilkan data pengumuman, dan dibawah pengumuman terdapat kalender aktif yang menyesuikan setingan date aktif. Berikut tampilan sidebar kiri.

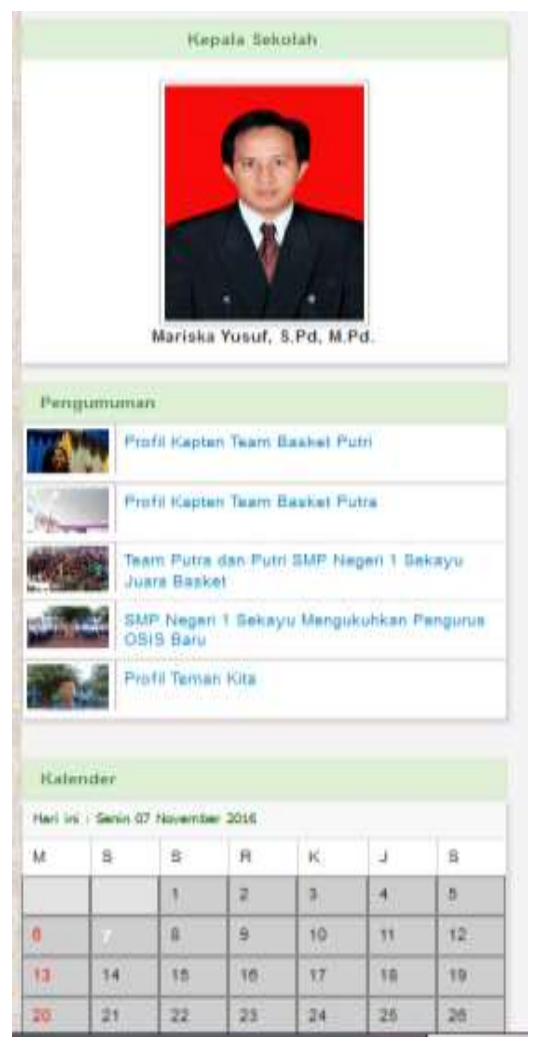

Gambar 12. Sidebar Kiri

\section{e. Tampilan Sidebar Kanan}

Pada sidebar kiri terdapat slide galeri foto guru, di bawahnya terdapat jam digital, di bawah jam terdapat absensi siswa yang digunakan untuk menampilkan data absensi siswa, dan dibawahnya terdapat data statistik pengunjung yang digunakan untuk menampilkan data pengunjung website SMP Negeri 1 Sekayu
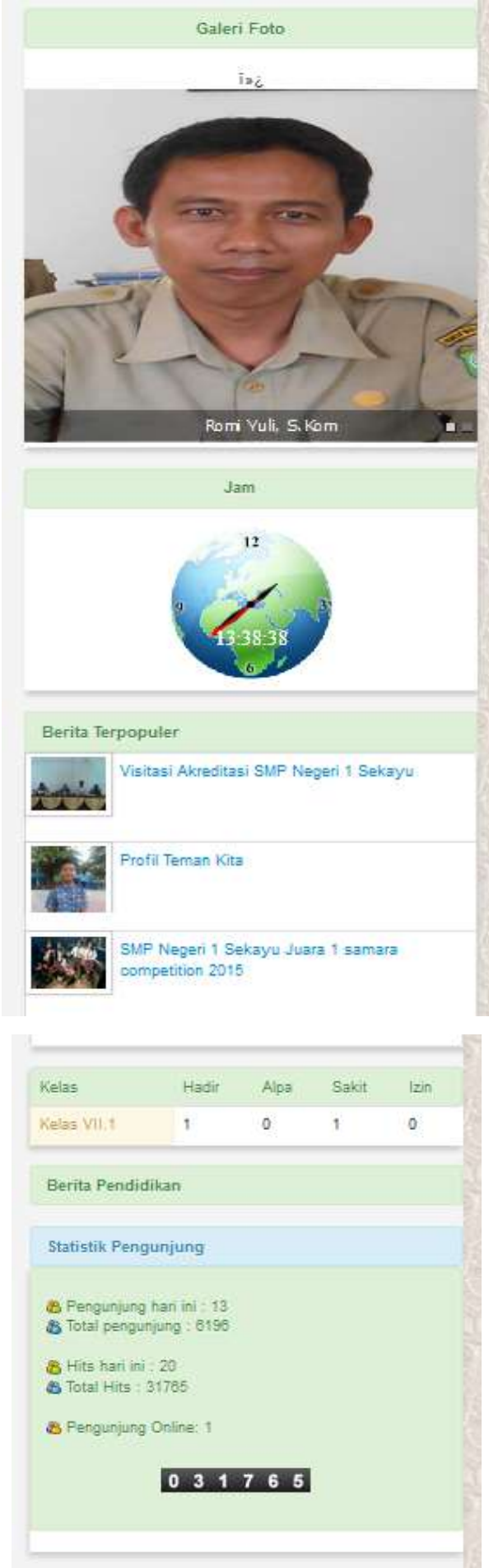

Gambar 13. Sidebar Kanan

f. Tampilan Form Login

Form Login digunakan untuk login baik siswa maupun guru dengan memasukan username, memilih level pengguna dan memasukan password yang dan selanjutnya 
menekan tombol sign in. Berikut tampilan

Form Login.

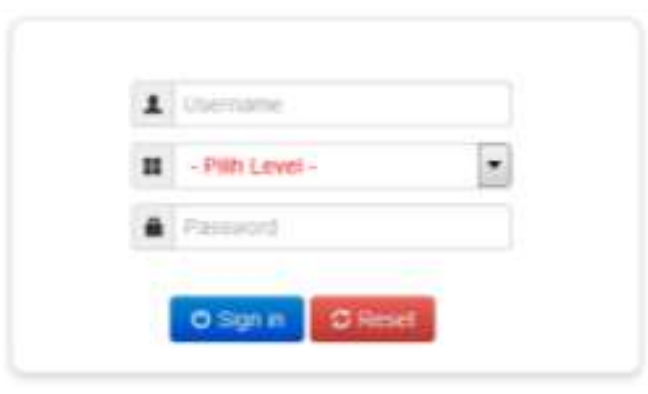

Gambar 14. Form Login

B. Struktur Database

Untuk mendukung file terus update pembangunan website SMP Negeri 1 sekayu menggunakan database MySQL, yang terdiri dari beberapa tabel yang saling berrelasi, berikut class diagram website SMP Negeri 1 Sekayu.

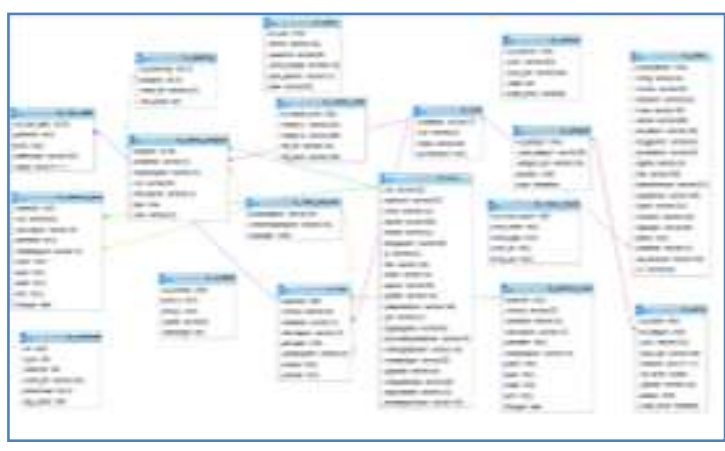

Gambar 15. Struktur database

\section{SIMPULAN}

Setelah melakukan serangkaian proses

UCD, maka dapat diambil kesimpulan bahwa dengan menerapkan metode UCD pada webiste SMP Negeri 1 Sekayu, dapat meningkatkan kegunaan (usability). Aplikasi website juga sudah cukup memenuhi prinsip-prisip perancangan interface pada UCD dan karateristik usability itu sendiri. Berdasarkan analisis dan pengujian yang telah dilakukan maka dapat diambil beberapa kesimpulan antara lain :
1. Dengan menerapkan metode UCD pada aplikasi website SMP Negeri 1 Sekayu telah dapat meningkatkan kegunaan (usability) website tersebut dan sesuai dengan karateristik usability yaitu learnibility, efficiency, satisfaction, memorability, dan errors.

2. Aplikasi website yang dibangun sudah cukup mudah dimengerti dan digunakan dengan baik oleh pengguna.

3. Dengan menggunakan analisis UCD, ditemukan saran dari pengguna untuk melakukan tambahan fitur pada website.

4. Website SMP Negeri 1 Sekayu dapat dijadikan sarana pembelajaran akademik di sekolah dengan memanfaatkan fitur yang ada.

\section{DAFTAR RUJUKAN}

Application Programming Interface.(2009) apihttp://ipangsan.web.id/apiapplication-program-interface.

Atha.(2008). Rancangan Sistem Pameran Online Menggunaka Metode UCD (User Centered Design). http://onlytha.blogspot.com/2008/12/ran cangan-sistem-pameran-online.html

Babbie, E. (1992). The Practice of social research (6th ed). California :

Wadsworth Publishing Company. http://elib.unikom.a.id/download.php?id=85606 Karat, J. (1997). User-Centered Software Evaluation Methodologies. Handbook of human Computer Interaction.M.G.Halander,Elsevier Science.

Sisfika Yanti Silalahi, Jurnal "Implementation Of User Centered Design Methods To Increase Usability In Social Media Application Client (Microblog) WebBased".

Lilis dwi farida, jurnal "pengukuran user experience dengan pendekatan usability (studi kasus: website pariwisata di asia tenggara)" 
Kurniawan Ardhi, jurnal "Perancangan CRM

(Customer Relationship Management)

Pada PO Dedy Jaya Berbasis Website

Menggunakan". Metode User Centered

Design (UCD) Sebagai Upaya Menjaga Kesetiaan Pelanggan"

Pengertian Prototyping. (2008)

http://www.google.com/url?sa=t\&source $=$ web $\& c d=1 \& v e d=0 C B U Q F j A A \& u r l=h$ ttp://fenni.staff.gunadarma.ac.id/Downlo ads/files/11018/Prototyping.pdf\&ei=Deo FTZTqA8LJrAeGqImRD,

Pengertian Application Programming Interface. http://pdfdatabase.com/search/pengertian -application-programminginterface.html.

Sigit Hadi Prayoga, Dana Indra Sensuse.jurnal "Analisa Usability Pada Aplikasi Berbasis Web Dengan Mengadopsi Model Kepuasan Pengguna (User Satisfaction)", 